\title{
Effect of Chemical Mutagens on Vegetative Growth and Flowering in Calendula Officinalis L. (Cv. Calypso Yellow
}

\author{
Yasser I. El- Nashar ${ }^{1}$
}

\begin{abstract}
The experiments were carried out to study the effect of different concentrations of two chemical mutagens; Sodium Azide (SA) and Diethyl Sulphate (DES); on some morphological traits in the M1-and M2-generations of Calendula officinalis (L.) c.v. Calypso Yellow. Seeds were treated with different SA and DES concentrations : 0 ( distilled water), 1000, 2000, 3000, 4000 and $5000 \mathrm{ppm}$. Germination percentage, plant height, number of leaves, number of branches, fresh weight, dry weight, number of inflorescences, inflorescences diameter, flowering date, leaf total chlorophyll, and root length were recorded. Both chemical mutagens was found to have significant effects in M1- generation with respect to dry weight, inflorescences diameter, flowering date, total leaf chlorophyll. The results clarified that DES significantly increased dry weight, total leaf chlorophyll. The different concentrations had significant effect in M1- generation with respect to seed germination percentage, plant height, number of leaves, fresh weight, flowering date, inflorescences diameter, total leaf chlorophyll content. While both chemical mutagens have significant effect the M2- generation with respect to number of leaves, leaf area, fresh weight, number of inflorescences, inflorescences diameter, flowering date and root length. The interaction between the two chemical mutagens and the concentrations treatments exerted significant effects for most of the studied parameters.
\end{abstract}

Keyword: Calendula officinalis, chemical mutagens, Sodium Azide, Diethyl Sulphate, SA, DES.

\section{INTRODUCTION}

Calendula is a genus that belongs to the family compositae with 15 species of herbs chiefly from the Mediterranean region, Canary Island to Iran. The common cultivated species are annuals, perennials, shrubs or really biennials with alternate simple leaves, mostly large heads with yellow or orange rays.

The main objective of this research was to study the effects of different concentrations of two mutagenic reagents Sodium Azide (SA) and Diethyl Sulphate (DES) on the morphological characteristics of Calendula officinalis L. cv. "Calypso Yellow" (pot marigold) as well as on the possibility of the induction of mutations.

For breeding purposes, it seems necessary to induce artificially new genetic variability by means of the chemical mutagens EMS, SA and DES in plant mutation programs (Hussein et al. 1974; Abd El-
Maksoud and El- Mahrouk 1992 and Vandana 1994; ElNashar, 2006). In this article, the effects of different chemical mutagens rates on vegetative and flowering growth of the first season, M1- and M2- generations Calendula officinalis $\mathrm{L}$. were evaluated. This study was carried out to find the possibility of inducing changes in Calendula officinalis L. which can be of value for improving this plant.

\section{MATERIALS AND METHODS}

This research was carried out in the greenhouses area of the Department of Plant Production - College of Food and Agriculture Sciences - King Saud University during the years 2009/2010 and 2010/2011.

\subsection{Plant materials}

Calendula officinalis L. cv. "Calypso Yellow" were used in this study. Seeds were obtained from " Sakata's Reliable seeds ", U. S. A. Seeds were treated with different SA and DES concentrations on December 8, 2009 and October 7,2010; for the first season, M1and M2- generations respectively. The concentrations used were : 0 (distilled water), 1000, 2000, 3000, 4000 and $5000 \mathrm{ppm}$. Plants were repotted in the final $15 \mathrm{~cm}$. pots.

Twenty percent of the survived M1- plants at each treatment were selected and selfed (Moh and Smith, 1951and Sinhamaha - parta and Rakshit, 1990) in order to obtain the M2- seeds.

\subsection{Chemical mutagens}

The chemicals used in the study were: Sodium Azide (SA) and Diethyl Sulphate (DES), obtained from Merck Co., Germany.

\subsection{Experimental design}

The layout of the experiment for the M1generation was a spilt plot design, with three replicates (Snedecor and Cochran, 1967). Every replicate contained 12 treatments, (two kinds of chemical mutagens and six concentrations). The main plot represented the two chemical mutagens. The sub plot represented the concentrations. 50 seeds were used for each treatment in every replicate; the total number of seeds used in the experiment was 1800 seeds per season.

\footnotetext{
${ }^{1}$ Botanical Garden Research Al-Montaza, Horticultural Research Institute, A.R.C. Alex. Egypt.

Received June 4, 2012, Accepted June 28, 2012
} 


\subsection{Experimental data}

Unless otherwise stated, the following parameters were recorded in the first of the successive experimental season:-

2.4.1.Seed germination percentage:- 8 weeks after sowing.

2.4.2.Plant height (cm):- measured from the soil surface to the upper growing point, after 4- 6 months from sowing.

2.4.3.Number of main branches per plant:- after 4-6 months from sowing.

2.4.4.Number of leaves per plant:- where 5 matured leaves were sampled, from the $3^{\text {rd }}$ node on the main stem of the chosen plant, 10 plants per plot were chosen at random to determine plant height, branching and leaf area.

2.4.5.Extraction of chlorophylls from leaves with $\mathrm{N}$, N-dimethylformamide (DMF) method .

Seedling (4 weeks-old) were grown in pots in a shade house. For chlorophyll analysis, A weight of leaflets about 0.025 to $.035 \mathrm{~g}$ were used to extract chlorophylls with $N, N$-dimethylformamide (DMF), by grinding with $2 \mathrm{ml}$ of solvent DMF in a mortar with pestle. The homogenate, combined with a further three washings of the pestle and mortar (each of $1.5 \mathrm{ml}$ ) with the same solvent, was centrifuged at 2500 r.p.m. in bench centrifuge for $10 \mathrm{~min}$. The pellet was then extracted with a further $1 \mathrm{ml}$ of solvent in homogenizer and the pooled supernatants adjusted to a final volume of $8 \mathrm{ml}$. The spectrum was recorded between 750 and $600 \mathrm{~nm}$. and the major red absorption peak automatically determined by the Pharmacia Biotech, Ultrospec 2000, UV/visible spectrophotometer recording spectrophotometer zeroed at $750 \mathrm{~nm}$. The Chls $a, b$, Chls $a+b$ concentrations in $\mu$ mo $1 / L$ and Chls ratio were then calculated using the equations described below (Porra et al., 1989):

Chl $a=13.43 A^{663.8}-3.47 A^{646.8}$

Chl $b=22.90 A^{663.8}-5.38 A^{646.8}$

Chl $a+b=19.43 A^{663.8}-8.05 A^{646.8}$

2.4.6.Fresh weight:- each of the vegetative growth and inflorescences was measured in grams.

2.4.7.Dry weight:- each of the vegetative growth and inflorescences was measured after oven drying for 4 days at $70^{\circ} \mathrm{C}$.

2.4.8.Flowering date:- expressed as the number of days from sowing to the appearance of the first inflorescence on the plant.

2.4.9.Number of inflorescences per plant:- Expressed as the average number of inflorescences per plant, where 10 plants from each treatment in every replicate were chosen at random. These chosen plants were also used to select the following flowering data.

2.4.10.Inflorescences diameter:- The head diameter was measured at the end of the experiments by measuring the diameter of the main head.

2.4.11.Root length:- measured from the soil surface to the upper growing point under soil, after 4- 6 months from sowing.

\section{RESULTS AND DISCUSSION}

\subsection{Seed germination (\%)}

The mean values for the chemical mutagens were found not significant in the M1-and M2- generations (Table 1). The effect of the different concentrations on seed germination was significant in M1-and M2generations. There was an apparent trend towards decreasing the germination percentage with increasing the chemical concentration from $1000(35.17 \%$, M1 and $47.16 \%$, M2) to $5000 \mathrm{ppm}$. (13.17\%, M1 and $11.03 \%$, $\mathrm{M} 2)$, as compared with the control $(36.33 \%, \mathrm{M} 1)$ and $(47.16 \%, \mathrm{M} 2)$.

The interactions between mutagens and concentrations were not significant in M1-generation, while were significant in M2- generation. In M2generation, the lowest seed germination percentage was recorded at the $5000 \mathrm{ppm}$. SA $(11.67 \%)$, DES $(10.33 \%)$, while the highest values were obtained at the concentration of 1000 ppm. SA (49.05\%), DES $(45.33 \%)$. The changes in the results of germination percentage of the M1 and M2- germinations from season to another may be due to the environmental effects, seed moisture content as well as the chemical concentrations rate (Abd El- Maksoud and ElMahrouk, 1992).

These results are similar to the findings of many investigators, who indicated that there were some stimulation effects on the germination of seeds as a results of treating the seeds with low concentrations of mutagenic chemicals as found by Badr et al. (2000) on Tagetes erecta; and El- Nashar (2006) on Amaranthus. The stimulating effect of the low and sometimes intermediate concentrations of the SA and DES on the seed germination may be due to enzymatic activation and awakening meristemic cell division in seed.

\subsection{Plant height}

The results showed that there were no significant differences among the different chemical mutagens in M1- and M2- generations, while there were significant differences between concentrations and the interactions between mutagens and concentrations in both generations (Table 1). 


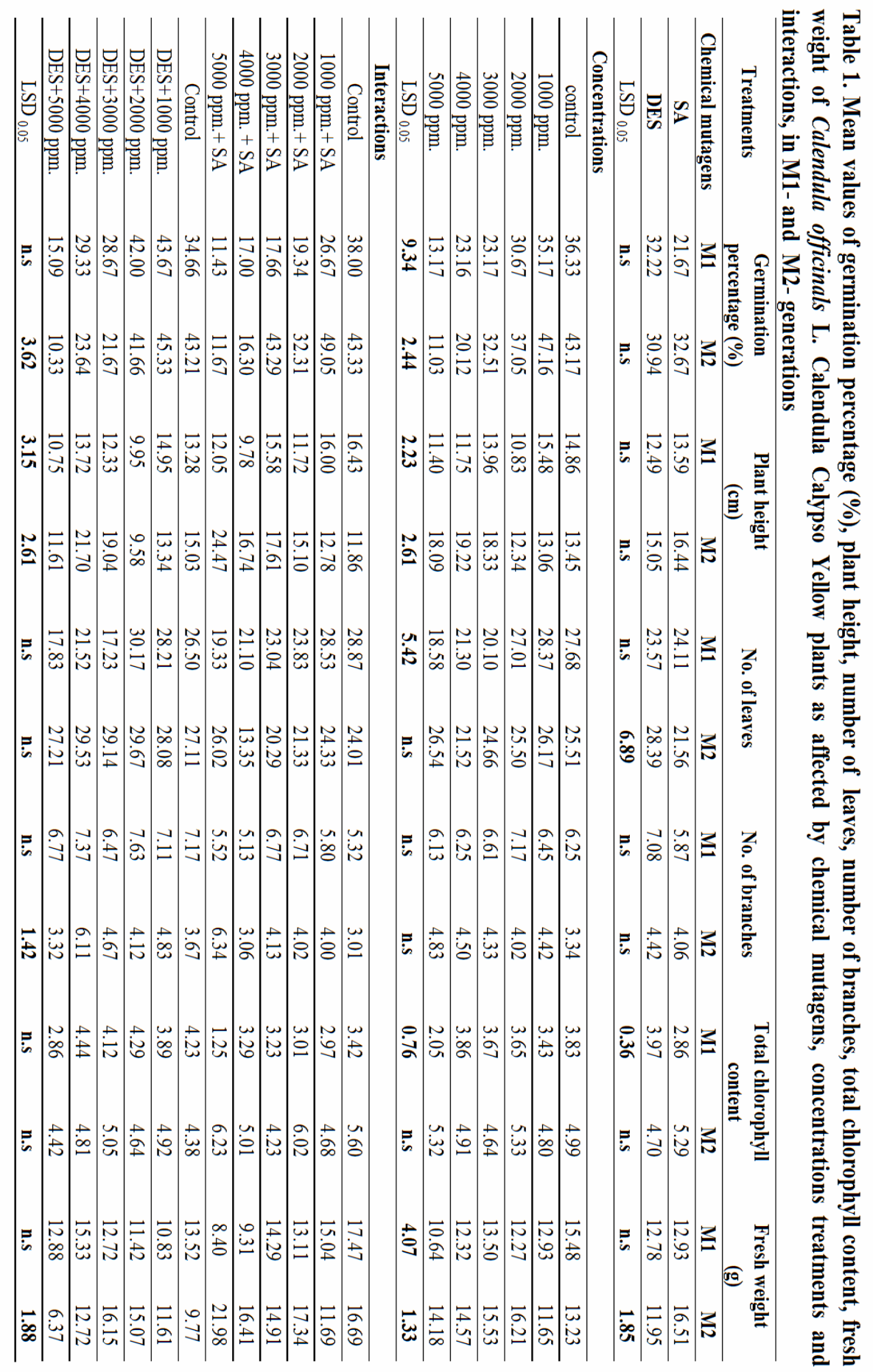


The concentration of 2000 ppm. (10.83 cm., M1) and $(12.34 \mathrm{~cm} ., \mathrm{M} 2)$ treatment had the smallest mean of plant height, while the greatest plant heights were detected at the concentrations of $1000 \mathrm{ppm} .(15.48 \mathrm{~cm}$., M1) and $4000 \mathrm{ppm}$. (19.22 cm., M2). The comparison between the different means of interaction indicated that the maximum average plant height was produced by control SA $(16.43 \mathrm{~cm} ., \mathrm{M} 1)$ and $5000 \mathrm{ppm}$. SA (24.47 cm., M2), while the minimum average plant height was detected at $4000 \mathrm{ppm}$. SA $(9.78 \mathrm{~cm} ., \mathrm{M} 1)$ and 2000 ppm. DES (9.58 cm., M2).

These results were similar to the findings of Hussein et al. (1974) on Salvia splendens; El- Torky (1992) on Euonymus japonicus; and El- Nashar (2006) on Amaranthus.

The stimulatory effect of lower concentrations recorded for plant height agreed completely with the findings of Warfield (1973) on Saintpaulia ionantha; and Abd El- Maksoud and El- Mahrouk (1992) on Asparagus densiflorus. These results might be attributed to the physiological damage caused by SA and DES and its hydrolysis products.

\subsection{Number of leaves per plant}

The mean values for mutagens was not significant in M1-generation, while it was significant in the M2(Table 1). The concentrations had significant effects in M1- generation, the highest number of leaves per plant was detected at the concentrations of 1000 ppm. (28.37, $\mathrm{M} 1$ ), while the lowest numbers were detected at the concentrations of $5000 \mathrm{ppm}$. (18.58, M1).

The interactions between mutagens and concentrations were not significant either in the M1- or the M2- generations.

There was apparent trend towards decreasing the number of leaves per plant with increasing the chemical concentration from 1000 to $5000 \mathrm{ppm}$. These results seemed to agree with those reported by Warfield (1973) on Saintpaulai ionantha; Hussein et al. (1974) on Salvia splendens; and El- Nashar (2006) on Amaranthus; These results might be attributed to the physiological effect of SA and DES, and its hydrolysis products. The effect may by due to the sensitivity of the different plant to the used concentrations variability of the chemical mutagens.

\subsection{Number of branches per plant}

The mean values for the chemical mutagens, concentrations and interactions between the two factors (Table1) proved to have no significant effect in M1-and M2-generations, but the interactions were significant in M2- generation. The greatest. number of branches per plant was observed at 2000 ppm. DES (7.63, M1), while the smallest mean of branches per plant was recorded at the control of SA (3.01, M2).

Some mutagen concentrations were able to increase the number of main branches per plant. These results are in conformity with those reported by Mahna et al. (1991) on Vigna aconitifolia.

\subsection{Total chlorophyll content}

The mean values presented in Table 2 showed significant effects in the M1- generation with respect to the chemical mutagens and the concentrations, but had no significant effects in the interactions in M1generation. All the data recorded for the M2-generation were not significant. The concentration of $5000 \mathrm{ppm}$. in the M1- (2.05) significantly reduced the total chlorophyll content, as compared with other treatments. Similar harmful effects were mentioned by Hussein et al. (1974) on Salvia splendens; Abd El- Maksoud and El- Mahrouk (1992) on Asparagus densiflorus; and ElNashar (2006) on Amaranthus; From the foregoing information, the effect of SA and DES which resulted in chlorophyll mutants can be attributed to enhancement in chloroplast differentiation.

The repositioning of the chromosome segments resulted in significant alteration in the yield and the pattern of distribution of EMS and SA induced chromatid aberration along the chromosomes. Although no direct relationship between particular reconstructions of karyo types and the reaction of individual genetic loci was established, a convincing evidence that the chromosome induction of gene mutation in plants was found (Gecheffe, 1998).

\subsection{Fresh weight of plant (g)}

In (Table 2), the mean values for the chemical mutagens and interactions between the two factors had

no significant effect in M1-generation, while all the data recorded for the M2-generation were found significant.

The effects of the higher mutagen concentration $5000 \mathrm{ppm}$. (10.64g) appeared significantly more harmful in the M1- generation, as compared with the control $(15.48 \mathrm{~g})$, but the greatest fresh weight was observed at 2000 ppm. (16.21g, M2).

Regarding the interactions, the lowest mean fresh weight of plant was detected at $5000 \mathrm{ppm}$. DES $(6.37 \mathrm{~g}$, M2), while the highest fresh weight was detected at 5000 ppm.SA (21.98g, M2).

The proportional increase and decrease in the fresh weight with increasing the SA and DES concentrations found in the present study were similar to findings of many investigators on other plants i.e. Baditescu et al. 


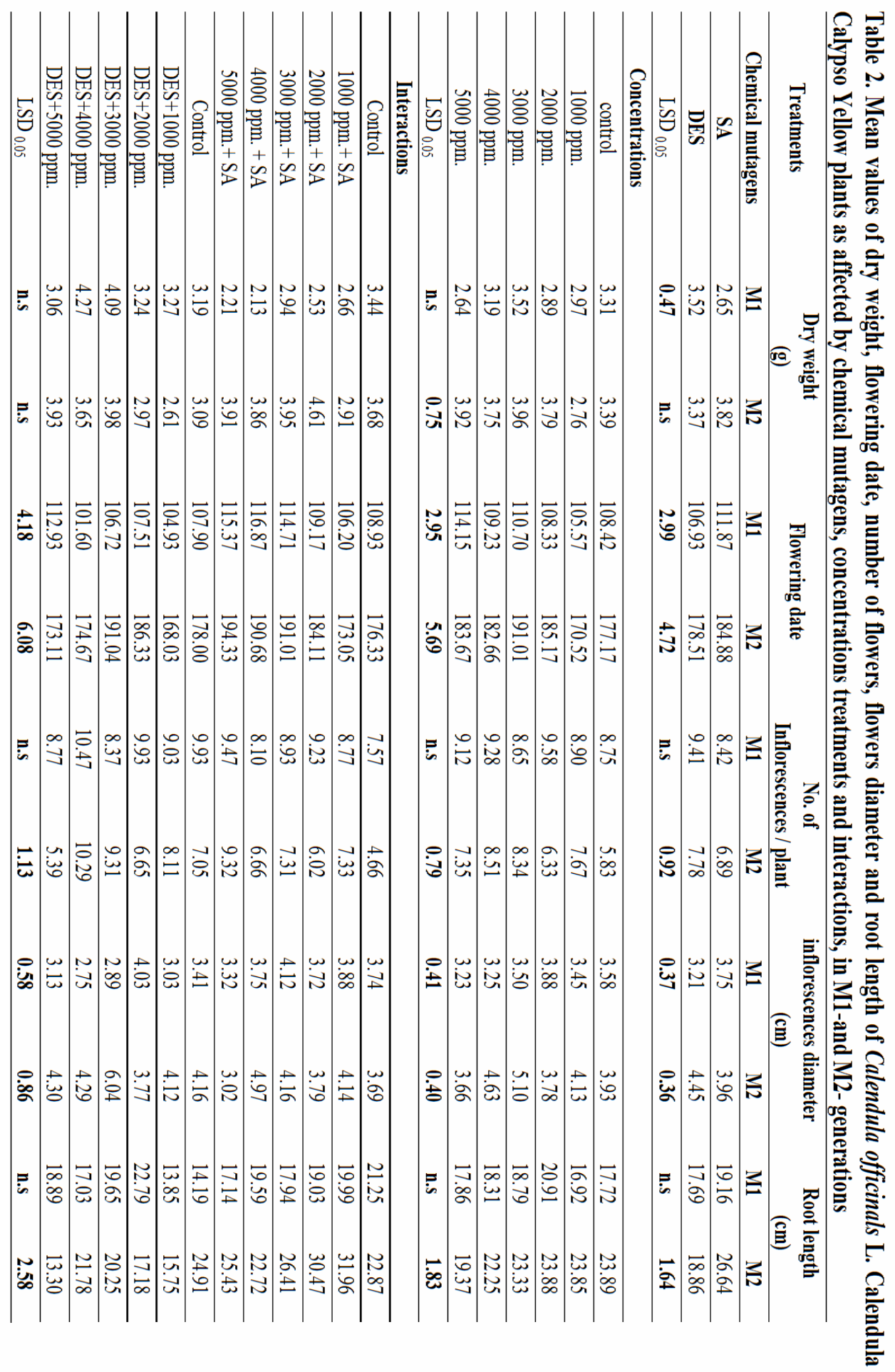


(1987) on grape vines; Krivitskii et al. (1990) on Amaranthus, and Abd El-Maksoud and ElMahrouk(1992) on Asparagus densiflorus. The variability between the different concentrations in M1and M2 can be attributed to the environmental factors prevailed during the growth period.

\subsection{Dry weight of plant (g)}

The mean values of dry weight for the chemical mutagens was found significant, while the concentrations and interactions had no significant effects in M1-generation (Table 2). The DES is relatively more effective and efficient than SA. The concentrations had significant effect in M2-generation, only.

The lowest mean dry weight was detected at the concentrations of $1000 \mathrm{ppm}$. (2.76 g, M2), while the highest dry weight was detected at 3000 ppm. (3.96 g, M2).

The proportional increase or decrease in the dry weight with increasing the SA and DES concentrations found in the present study was similar to the finding of Abd El- Maksoud and El- Mahrouk (1992) on Asparagus densiflorus. The variability between the chemical mutagens can be attributed to the environmental factors prevailed during the growth period.

\subsection{Flowering date (days)}

Data showed that the average number of days from seed sowing till the beginning of flowering was affected by the two factors. The chemicals, concentrations and the interactions had significant effects in M1-and M2generations (Table 2).

The earliest flowering dates were detected at the concentrations of $1000 \mathrm{ppm}$. (105.57days, M1) and (170.52days, M2), while the latest ones obtained at 5000 ppm. (114.15 days, M1) and 3000 ppm. (191.01 days, M2).

The concentrations 4000 ppm. SA (116.87 days, M1) and 5000 ppm. SA (194.33 days, M2) were the latest flowering dates than all.

Investigators reported that the effect of SA and DES on flowering date appears in two manners:-

A-Early flowering, as reported by Hussein et al. (1974) who found that the $0.3 \%$ EMS concentrations caused a significant response towards earliness on Salvia splendens; Asfar-Awan et al. (1981) and Rao and Reddi (1987) on rice ; and Adamska et al. (1996) on winter Swede rape Mordvinova et al. (1998) on maize.

B- Late flowering, which was reported by Hussein et al. (1974) who found that $0.1 \%$ and $0.2 \%$ EMS concentrations caused a slight delay in flowering on Salvia splendens; Rao and Reddi (1987) on rice; Mahna et al. (1991) on Vinga aconitifola; Reddy et al. (1994) on wheat.

The variability between them can be attributed to the environmental variation or to the response to the chemical mutagens and mutagen concentrations. It is Known that low and intermediate concentrations of these chemicals, generally, stimulate cell growth, increase the rate of growth and produce earlier flowering in specific cases as reported by Warfield (1973), Hussien et al. (1974) and Adamska et al. (1996). On the other hand, High concentrations of such chemical seemed to inhibit cell growth, decrease the rate of growth and delay the flowering as found and reported by Neagu (1984), Vandana and_Dubey (1993) and Khan et al. (1995), Badr et al. (2000) and ElNashar (2006).

\subsection{Number of inflorescences per plant}

The utilized SA and DES rates did not markedly affect the number of inflorescences per plant, since the data in (Table 2) show that neither chemical mutagens nor concentrations was changed by all different SA and DES rates in M1-generation, while the two chemicals, concentrations and the interactions had significant effect in the M2-generation.

The effects of the higher mutagen concentration $4000 \mathrm{ppm}$. (8.51, M2) appeared to give significantly higher number of inflorescences, as compared with the control $(5.83, \mathrm{M} 2)$.

The effects of the higher interactions of 5000 ppm.SA (9.32,M2) appeared significantly more effective, as compared with the control (4.66,M2).

\subsection{Inflorescence diameter $(\mathbf{c m})$}

Considering the M1-generation, (Table 2) shows that the differences between the two chemicals, concentrations and the interactions in both, M1- and M2-generations, were found significant compared with the control.

The lowest mean Inflorescence diameter were detected at the concentrations of $5000 \mathrm{ppm} .(3.23 \mathrm{~cm}$., M1) and $(3.66 \mathrm{~cm} ., \mathrm{M} 2)$, while the highest diameters were detected at the concentrations of $2000 \mathrm{ppm}$. (3.88cm., M1) and 3000ppm. (5.10cm., M2). Data revealed that the interaction of $3000 \mathrm{ppm}$. SA $(4.12 \mathrm{~cm}$., M1) and $3000 \mathrm{ppm}$. DES $(6.04 \mathrm{~cm}$., M2) were the highest diameter than all in the M1- and M2generations, respectively.

These results were in contrary with those mentioned by Mahna and Singh (1975), Pipie (1975) on pea; AlSaheal and Gamil (1982) on wheat; Vandana (1994) on Vicia faba; and El- Nashar (2006) on Amaranthus. 
Environmental and physiological conditions at the middle of the flowering period can affect inflorescence quality. The growth reaches its maximum, photoperiod was longer therefore the diameters of inflorescences were increased as a result of intensity and temperature were higher. The photosynthesis and production of carbohydrate and energy at the ideal rate, which led to the improving of the inflorescences quality giving the chance to the chemical agents to affect this characteristics.

\subsection{Root length $(\mathrm{cm})$}

In (Table 2), the mean values for the chemical mutagens, concentrations and interactions between the two factors had no significant effect in M1-generation, while they were significant M2-generation.

The effects of the higher mutagen concentration $5000 \mathrm{ppm}$. (19.37cm., M2) appeared significantly more harmful, as compared with the control $(23.89 \mathrm{~cm}$., M2).

The lowest mean root length was detected at the interactions between the two factors of $5000 \mathrm{ppm}$. DES $(13.30 \mathrm{~cm} ., \mathrm{M} 2)$, while the highest root length were detected at the concentrations of 1000 ppm. SA(31.96 cm.).

Root length is a quantitative character which can be affected by SA and DES treatments. In this respect, the absence of the induced variability may be attributed to environmental factors such as temperature, nutrition.

\section{REFERENCES}

Abd El-Maksoud, B. and E. M. El-mahrouk (1992). Effect of Ethyl methane sulfonate on the growth and interior quality of Asparagus densiflorus (Kunth) Jessop C.V." SPRENGERI" Egypt. J. Appl. Sci. 7 (10): 116 -132.

Adamska, E.; S. Jezowski; J. Olejniczak and W. Rybinski (1996). Effect of chemical mutagens on induced variation in winter Swede rape. Plant Breeding Abst. 66 (9): 1326 (9656).

Afsar-Awan, M.; C. F. Konzac; J. N. Rutger and R. A. Nilan (1981). Mutagenic effects of sodium azid in rice. Plant Breeding Abst. 51 (6) : 449 (5124).

Al- Saheal, Y. A. and K.H. Gamil (1982). Induced mutation of a Saudi Arabian local variety of bread wheat. I. Yield and yield components Plant Breeding Abst. 52 (9) : 672 (7345).

Baditescu, D. ; E. Brandusa and M. Ionescu (1987). Aspects of the use of somatic mutagenesis improving grape vines. Plant Breeding Abst. 57 (6) : (6463).

Badr, M.; M. El-Torky; Ola El-Shennawy and Y. El-Nashar (2000) Effect of chemical mutagens on Tagetes erecta. J. Agric. Sci. Mansoura Univ., 25(8): 5241-5256.

El- Nashar, Y. (2006). Effect of chemical mutagens ( Sodium Azide and Diethyl Sulphate ) on Growth, Flowering and induced variability in Amaranthus caudatus $L$. and A. hypochondriacus $L . \mathrm{Ph}$. D. Thesis Faculty of Agriculture, Alex. Univ. A.R.E.
El-Torky, M. G. (1992). Effect of EMS ( Ethyl methane sulphonate, on variegation type and some other horticultural traits in Euonymus japonicus, Linn. Alex. J. Agric. Res. 37 (1) : 249 - 260.

Gecheffe, K. (1998). Further evidence for position - specific effects in the action of Chemical mutagens in barley ( Hordeum vulgare L.) Plant Breeding Abst. 68 (5) : 635 (4450).

Hussein, H. A. S.; S. H. Sallam; H. A. Kamel and T. Labib (1974). The mutagenic effects of EMS on Saliva splendens. Egypt. J. Genet. Cytol. 30 : 193 - 203.

Khan, S.; B. A. Siddiqui and Mohammed Nadeem (1995). Variation in quantitative characters of mungbean after seed treatment with DES. ( C. F. Advances in Plant Sciences (1994)7 (1):41-45). Plant Breeding Abst. 65 (8): 759.

Koller ,H.B. (1972). Leaf area - leaf weight relationship in the soybean. Crop. Sci. 12:180- 183.

Krivitskii, K. N.; A. A. Abramov and I. P. Bidzyura (1990). First Soviet mutation of Amaranthus cruentus. Plant Breeding Abst. 60 (10) : 1230 (10055) .

Mahna, S. K. and Singh, D. (1975). Induced floral mutation in Physalis ixocarpa, Brot. Plant Breeding Abst. 45(9): 611(7723).

Mahna; S. K; A. Bhargva and L. Mohan (1991). Alkaline azide mutagenic in cowpea. Plant Breeding Abst. 61(6): 735 ( 5775).

Moh, C. C. and L. Smith (1951). An analysis of seedling mutatants (spontaneous, atomic bomb radiation and $\mathrm{X}-$ ray - induced) in barly and durum wheat. Genetics 36 : $629-640$

Mordvinova; M. Stoilov and V. N. Lysikov (1988). Effect of ecological conditions on genotypic variation in maize mutants under the influence of chemical mutagens. Plant Breeding Abst. 58 (10) : 865 (8352).

Neagu, M. (1974). Contributions on the mutagenic effect of diethyl Sulphate on Sunflower ( Helianthus annuus, L.). Plant Breeding Abst. 44 (10) : 588 (7094).

Pipie, A. (1975). Morphological mutations obtained in two pea varieties with diethyl sulphate and ethyl methanesulphate. Plant Breeding Abst. 45 (9): 623 (7885).

Porra, R. J., Thompson, W. A. and Kriedemann, P. E., 1989. Determination of accurate extinction coefficients and simultaneous equations for assaying chlorophylls $a$ and $b$ extracted with four different solvents: verification of the concentration of chlorophyll standards by atomic absorption spectroscopy. Biochemical et Biophysical Acta, 975, 384-394.

Rao, D. R. M. and T. V. V. S. Reddi (1987). Azide mutagenesis in rice. Plant Breeding Abst. 57 (1): 37 (326).

Reddy, V. R. K. ; K. N. Pushpaltha; R. Nalin and M. Indra (1994). Induced variability for different quantitative characters in hexaploid triticale. Plant Breeding Abst. 64 (9): 766 (8988).

Sinhamaha -patra, S. P. and S. C. Rakshit (1990). Respose to selection for plant height in X-ray treated population of jute (Corchorus caspularis L.) c.v. JRC 212 .Euphytica 51: 95 - 99. 
Snedecor, G. W. and W. G. Cochran (1967). Statistical Methods. Sixth Edition. Iowa state university press, U.S.A.

Vandana (1994). Studies on mutations induced by EMS and DES in faba bean II. Vital mutations affecting vegetative organs. Plant Breeding Abst. 64 (6): 842 (6147).
Vandana and D.K. Dubey (1993). Heritability and genetic advance in induced mutants of faba bean (Vicia faba L.). Plant Breeding Abst. 63 (4): 494 (4002).

Warfield, D. (1973). Induction of mutation in African violet (Saintpulia ionantha, Wendl.) by ethyl methane sulfonate. Hort. Science, 8 (1) : 29 - 31.

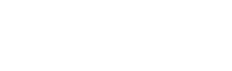

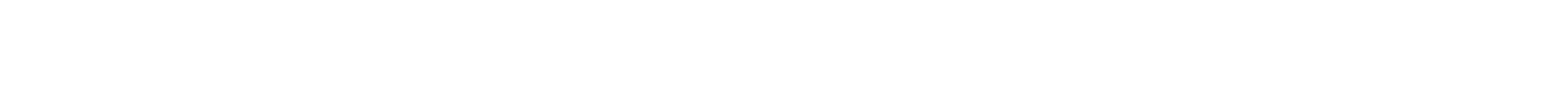
لالهمر

يلسر إلاعلى الششار

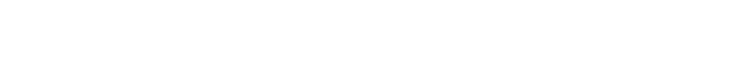

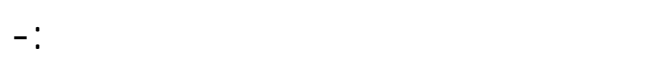

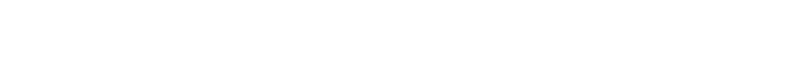

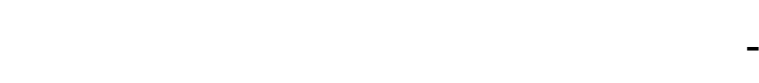

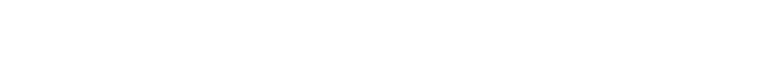
إلى وتاريخ الازهار قطار النوة.

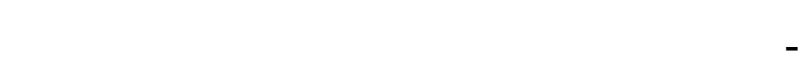

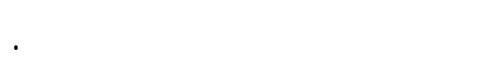

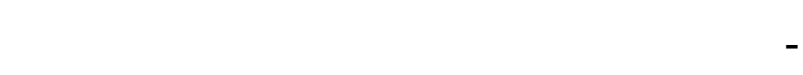

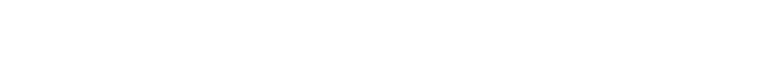
الرطب وتاريخ الازهار وتطر النورة.

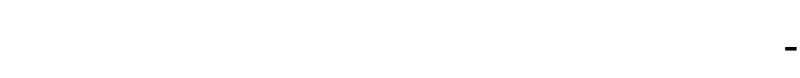
سلفلت على بض الصفلت الظاهرة $\square$ نبلت الكلانديولا

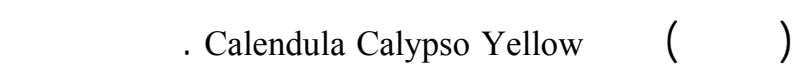
البذور تت الررلة بالزركزات الاتية من إلهفرل(SA)

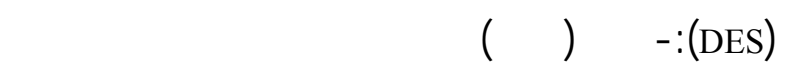
(0...

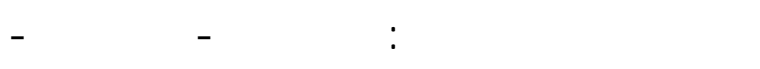

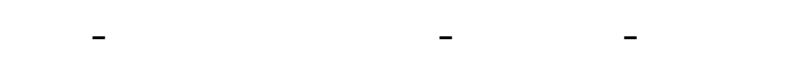
الرطب - الوزن الف - تاريخ الازهار - عدد النورات - طار النورة

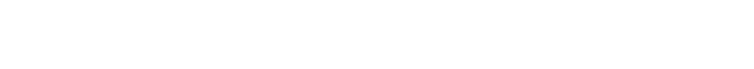

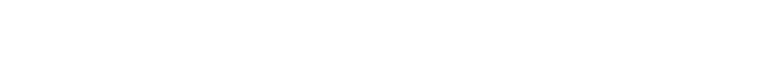
النورة وطول الصنر.

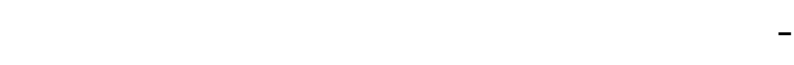
كلت معنوة التأنَ][م مغلم القيلست. 